Article

\title{
Cross-Linked Enzyme Aggregates of Feruloyl Esterase Preparations from Thermothelomyces thermophila and Talaromyces wortmannii
}

\author{
Anastasia Zerva ${ }^{1}$, Io Antonopoulou ${ }^{1}{ }^{(\mathbb{D})}$, Josefine Enman ${ }^{1}$, Laura Iancu ${ }^{2}$, Ulrika Rova ${ }^{1}$ (D) and \\ Paul Christakopoulos $1, *$ \\ 1 Division of Chemical Engineering, Department of Civil, Environmental and Natural Resources Engineering, \\ Luleå University of Technology, 97187 Luleå, Sweden; anastasia.zerva@ltu.se (A.Z.); \\ io.antonopoulou@ltu.se (I.A.); Josefine.Enman@ltu.se (J.E.); Ulrika.Rova@ltu.se (U.R.) \\ 2 DuPont Industrial Biosciences, Nieuwe Kanaal 7-S, 6709 PA Wageningen, The Netherlands; \\ Laura.Iancu@dupont.com \\ * Correspondence: paul.christakopoulos@ltu.se; Tel.: +46-920-492510
}

Received: 18 April 2018; Accepted: 10 May 2018; Published: 15 May 2018

\begin{abstract}
Cross-linked enzyme aggregates $\left(\right.$ CLEA $\left.^{\circledR}\right)$ technology is a well-established method in the current literature for the low-cost and effective immobilization of several enzymes. The main advantage of this particular method is the simplicity of the process, since it consists of only two steps. However, CLEA immobilization must be carefully designed for each desired enzyme, since the optimum conditions for enzymes can vary significantly, according to their physicochemical properties. In the present study, an investigation of the optimum CLEA immobilization conditions was carried out for eight feruloyl esterase preparations. Feruloyl esterases are a very important enzyme group in the valorization of lignocellulosic biomass, since they act in a synergistic way with other enzymes for the breakdown of plant biomass. Specifically, we investigated the type and concentration of precipitant and the crosslinker concentration, for retaining optimal activity. FAE68 was found to be the most promising enzyme for CLEA immobilization, since in this case, the maximum retained activity, over $98 \%$, was observed. Subsequently, we examined the operational stability and the stability in organic solvents for the obtained CLEA preparations, as well as their structure. Overall, our results support that the maximum activity retaining and the stability properties of the final CLEAs can vary greatly in different FAE preparations. Nevertheless, some of the examined FAEs show a significant potential for further applications in harsh industrial conditions.
\end{abstract}

Keywords: cross-linked enzyme aggregates; feruloyl esterases; ferulic acid; enzyme immobilization

\section{Introduction}

The immobilization of enzymes using cross-linked enzyme aggregates (CLEA) technology has gained significant attention in the last 20 years, with a wide variety of enzymes and enzyme mixtures being immobilized with standard or modified CLEA methodologies. The popularity of CLEA immobilization is mainly due to the simplicity and the low cost of the process. CLEA immobilization consists of only two steps: the precipitation and the cross-linking step [1]. The crosslinking of the proteins is unspecific, and thus, inexpensive, bulk chemicals can be used as reactants for the completion of the process. Moreover, the overall process does not require any solid support, minimizing the cost of the procedure and making it competitive with other immobilization methods, where a solid matrix is required, which often has to be tailored to the individual nature of the target enzyme (such as size, hydrophilicity, etc.) [2]. However, due to the very low specificity of the process, the optimal conditions 
of the immobilization must be very carefully chosen for the desired biocatalyst, because even enzymes with very similar physicochemical characteristics might require quite different conditions for optimum retention of activity after immobilization. For this purpose, a detailed optimization protocol is required for the efficient CLEA immobilization of any given biocatalyst.

Various different enzymes have been immobilized in CLEA form, among them lipases, esterases, laccases, hydrolases and others [1]. For some of these enzymes, a great loss of activity is observed in the final product [3], while in several cases, an improved activity is achieved [4] and even modifications of the original properties, such as the substrate specificity [5]. Nonetheless, most of the available data support a certain degree of improved stability in the immobilized enzymes, such as thermostability and solvent stability, as well as operational stability properties [6]. All these characteristics are very attractive for the design of biocatalysts for industrial use, and for this purpose, some groups have tried to design bioreactor configurations, dedicated to the optimum large-scale use of CLEAs, for various biotransformations $[7,8]$.

Feruloyl esterases (FAEs, 4-hydroxy-3-methoxycinnamoyl-sugar hydrolase EC 3.1.1.73) belong to the enzymatic machinery of various lignocellulose-degrading microorganisms, and their specific role is the hydrolysis of the ester bond between the hydroxycinnamic acids and sugar moieties of hemicellulose [9]. The most studied example of such a reaction is the cleavage of the bond between ferulic acid and arabinose. In this sense, these enzymes act synergistically with xylanases for the degradation of plant biomass. FAEs have been widely used for the production of free ferulic acid (FA) from renewable resources, such as wheat bran [10], wheat straw [11], brewer's spent grain [12] and others. FA is widely known for its antioxidant properties, and for this purpose, it is used today in cosmetic products, such as C E FERULIC ${ }^{\circledR}$ Serum by the company SkinCeuticals, as a food preservative [13] and as a building block for the production of several chemicals, such as polymers, protocatechuic acid derivatives and catechol derivatives, mainly vanillin [14]. Therefore, the widespread industrial use of FA has led to significant research efforts for the discovery, characterization, heterologous expression and mode of action of several FAEs [14-17], aiming at the complete elucidation of their action mechanism, on the one hand, and at the development of industrially-attractive biocatalyst preparations, on the other. The main focus of the present work was the improvement of the stability and reusability properties of eight different commercial FAE preparations, through CLEA immobilization. To elucidate this, we investigated the optimum conditions for CLEA formation, and subsequently, we characterized the resulting FAE preparations.

\section{Results}

\subsection{Effect of Precipitants on CLEA Preparation}

The selection of the precipitating agent is of crucial importance for CLEA preparations, because it should not have a detrimental effect on the enzyme activity. In the present study, four precipitants were tested towards their effect on the residual FAE activity: saturated ammonium sulfate, tert-butanol, acetone and PEG-4000. The results are presented in Figure 1.

It is obvious that the precipitating agent is of crucial importance for the residual activity recovered after CLEA formation. In most cases, the tert-butyl alcohol and acetone seem to have a detrimental effect on the activity of the FAEs CLEA, except from FAEA2 and FAEB1, where they were found to be among the best precipitants. On the other hand, ammonium sulfate or PEG-4000 were found to be the best for all other FAEs, with maximum recovery of activity $98.7 \%$ in the case of the PEG-4000 precipitation of FAE68. FAE68, on the other hand, seems to perform best after CLEA immobilization, seeing that in this case, the maximum residual activities were observed after cross-linking. Similar to the other FAEs, FAE68 retains less than $40 \%$ of the initial activity when acetone and tert-butyl alcohol were used as precipitants, but in the case of ammonium sulfate or PEG-4000, FAE68 retains almost completely the initial activity after immobilization $(83.8 \%$ and $98.7 \%$ for ammonium sulfate and PEG-4000, respectively). For the subsequent experiments, ammonium sulfate was selected for 
FAEs A1, B1, B2 and 125; PEG-4000 was selected for FAEs 68, 7262 and MtFae1a; and tert-butyl alcohol was selected for FAEA2.

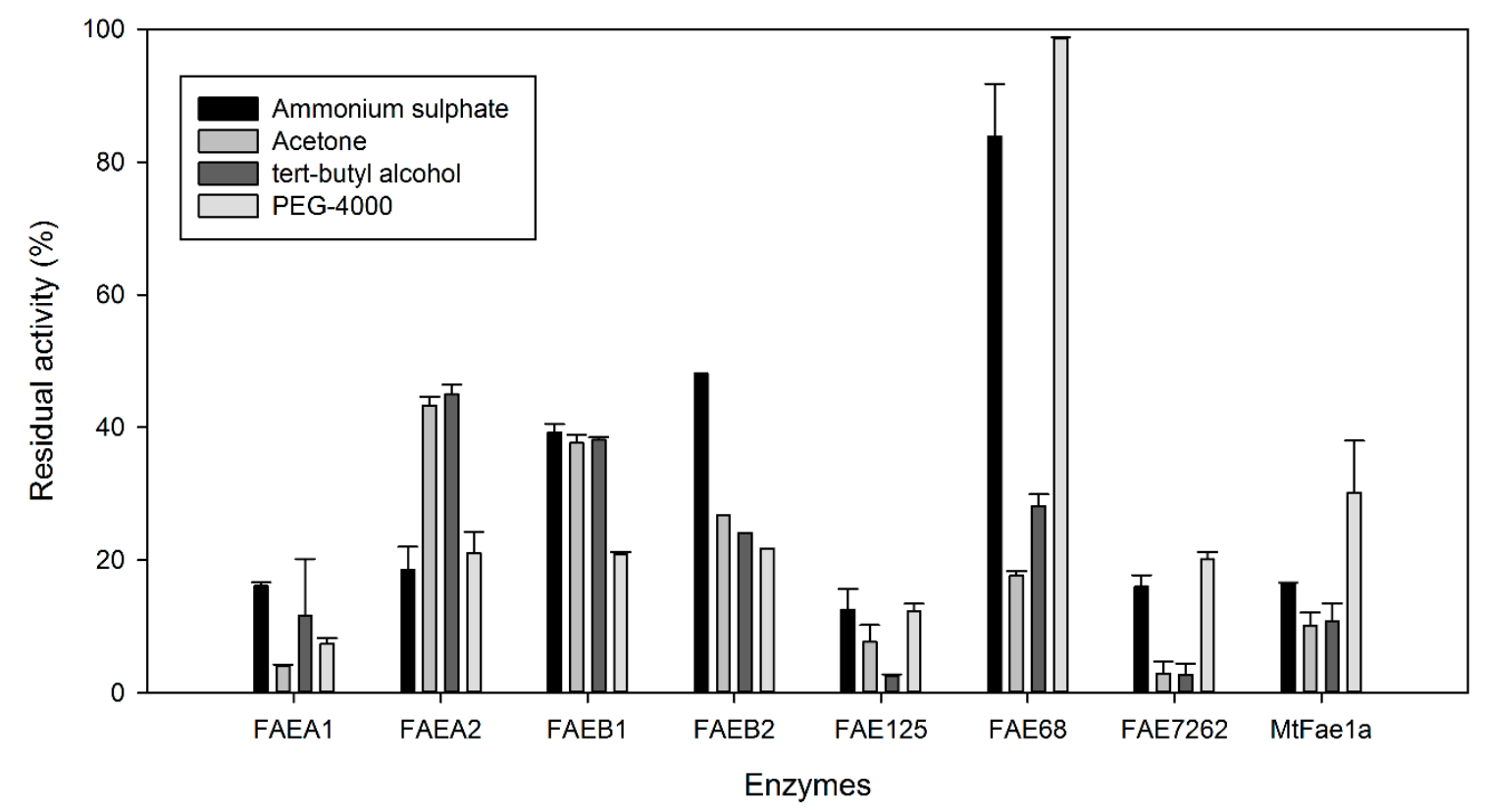

Figure 1. Effect of precipitants on the activity of cross-linked enzyme aggregates (CLEA)-immobilized FAEs. Activity is presented as a percentage of the initial activity of the free enzyme. Reactions were performed as described in Section 4.2. Initial activity values for each FAE were as follows: FAEA1 $4.99 \mathrm{U} \mathrm{mL}^{-1}$, FAEA2 $1.29 \mathrm{U} \mathrm{mL}^{-1}$, FAEB1 $3.65 \mathrm{U} \mathrm{mL}^{-1}$, FAEB2 $1.84 \mathrm{U} \mathrm{mL}^{-1}$, FAE125 $1.25 \mathrm{U} \mathrm{mL}^{-1}$, FAE68 4.99 $\mathrm{U} \mathrm{mL}^{-1}$, FAE7262 $3.38 \mathrm{U} \mathrm{mL}^{-1}$, MtFae1a $2.71 \mathrm{U} \mathrm{mL}^{-1}$.

\subsection{Effect of Glutaraldehyde Concentration on CLEA Activity}

Cross-linker concentration is also a very important parameter for the immobilization of enzymes in CLEAs. Low concentrations of the cross-linker might result in loss of CLEA activity due to free enzyme, but very high concentrations of the cross-linker might also lead to significant activity loss, due to the production of bigger aggregates with substrate mass diffusion limitations, as well as higher rigidity of the enzyme. As a result, the concentration of the cross-linker must be minutely fine-tuned, in order to obtain the best possible results. In the present study, glutaraldehyde was used as a cross-linker in four different concentrations, using the optimum precipitants selected from the previous optimization step. Glutaraldehyde is a very common cross-linker for CLEA formation, being applicable to most enzymes [1]. The results of the effect of glutaraldehyde concentration on the CLEA activity are shown in Figure 2.

In accordance with the results of the previous experiment, FAE68 was found to retain the initial activity almost completely, seeing that in all glutaraldehyde concentrations, the residual activity observed was $>97 \%$. On the other hand, glutaraldehyde was found to lower the activity of FAE7262 significantly: the maximum residual activity in this case was observed in the lower glutaraldehyde concentration tested $(10 \mathrm{mM})$. FAEA2 was the enzyme with the lowest CLEA yield for all glutaraldehyde concentrations, while the residual activity of FAEB2 reached $68.8 \%$ with $300 \mathrm{mM}$ glutaraldehyde (Figure 2). The remaining soluble FAE activity in the supernatant of the crosslinking reaction was also measured, and for most FAEs, the increase in glutaraldehyde concentration led to lower residual activity for soluble enzymes (Figure S1). The optimum glutaraldehyde concentration for the cross-linking of each enzyme was selected for further experiments, as follows: FAEA1: $200 \mathrm{mM}$, FAEA2: 50 mM, FAEB1: 200 mM, FAEB2: 300 mM, FAE125: 200 mM, FAE68: 200 mM, FAE7262: $10 \mathrm{mM}$, MtFaela: $10 \mathrm{mM}$. 


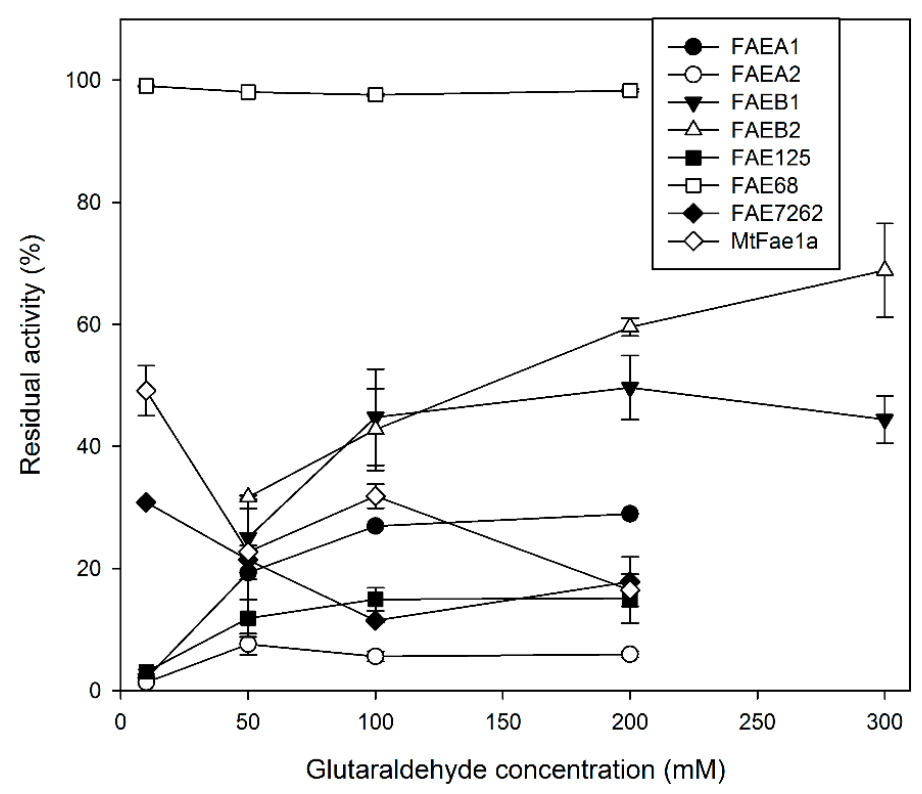

Figure 2. Effect of glutaraldehyde concentration on the activity of CLEA-immobilized FAEs. Residual activity is presented as a percentage of the initial activity of the corresponding free enzymes. Reactions were performed as described in Section 4.2. Initial activity values for each FAE were as follows: FAEA1 1.85 $\mathrm{U} \mathrm{mL}^{-1}$, FAEA2 $3.36 \mathrm{U} \mathrm{mL}^{-1}$, FAEB1 $3.57 \mathrm{U} \mathrm{mL}^{-1}$, FAEB2 $2.62 \mathrm{U} \mathrm{mL}^{-1}$, FAE125 $1.25 \mathrm{U} \mathrm{mL}^{-1}$, FAE68 $4.98 \mathrm{U} \mathrm{mL}^{-1}$, FAE7262 $3.38 \mathrm{U} \mathrm{mL}^{-1}$, MtFae1a $2.71 \mathrm{U} \mathrm{mL}^{-1}$.

\subsection{Stability of CLEAs in Organic Solvents}

The stability of the obtained CLEAs, at optimum immobilization conditions, was tested in regard to several organic solvents, commonly used in various applications. The results of the residual activity, after $24 \mathrm{~h}$ of incubation at $25^{\circ} \mathrm{C}$, are shown in Figure 3 and are expressed as a percentage of residual activity with respect to control incubations in MOPS-NaOH buffer $100 \mathrm{mM}, \mathrm{pH} 6$.

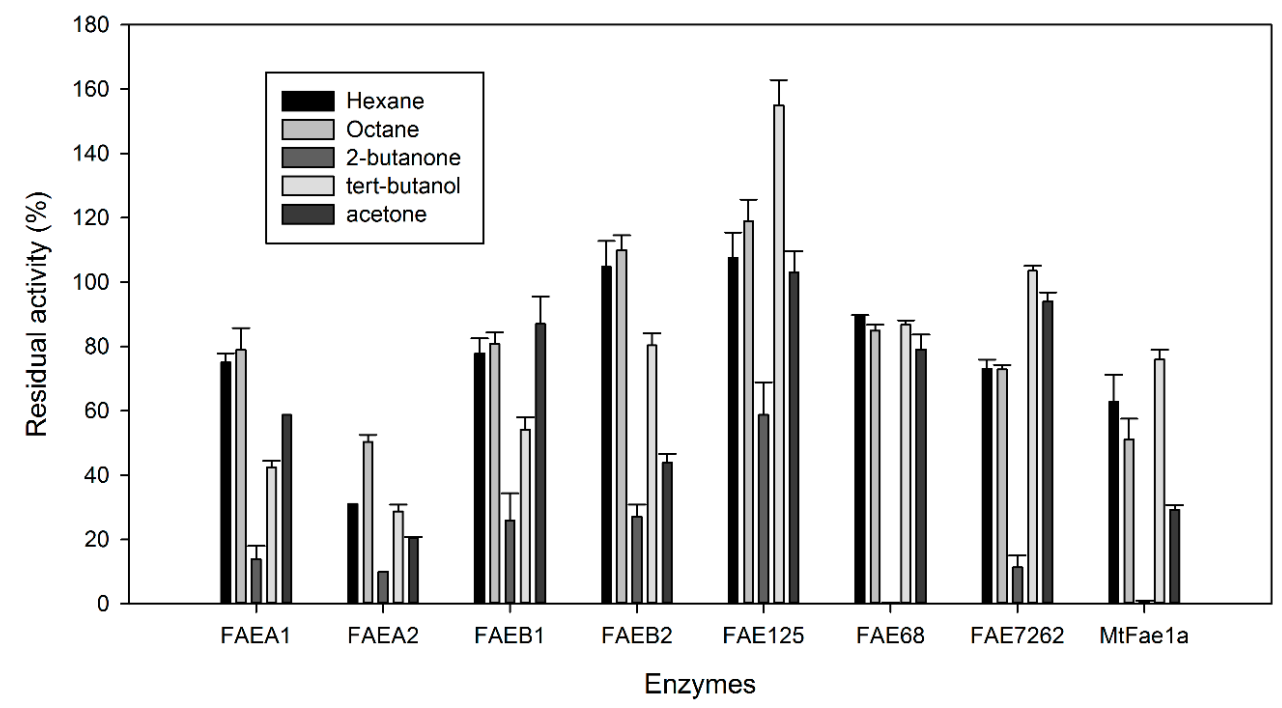

Figure 3. Stability of FAE CLEAs in organic solvents. The CLEAs were incubated at $25{ }^{\circ} \mathrm{C}$ for $24 \mathrm{~h}$, and the residual activity was expressed as a percentage of the activity of control incubations, in MOPS-NaOH buffer (100 mM, pH 6). Reactions were performed as described in Section 4.2. Initial activity values for each FAE were as follows: FAEA1 $0.63 \mathrm{U} \mathrm{mL}^{-1}$, FAEA2 $0.08 \mathrm{U} \mathrm{mL}^{-1}$, FAEB1 $1.73 \mathrm{U} \mathrm{mL}^{-1}$, FAEB2 $0.64 \mathrm{U} \mathrm{mL}^{-1}$, FAE125 $0.13 \mathrm{U} \mathrm{mL}^{-1}$, FAE68 $4.98 \mathrm{U} \mathrm{mL}^{-1}$, FAE7262 $0.75 \mathrm{U} \mathrm{mL}^{-1}$, $\mathrm{MtFae1a} 1.46 \mathrm{U} \mathrm{mL}^{-1}$. 
From the results shown in Figure 3, it is obvious that stability in organic solvents varies significantly according to the tested enzyme and the solvent. For example, FAE125 retains most of its activity in all the tested solvents, except 2-butanone, where the activity is significantly lower. Generally, 2-butanone was found to have the most damaging effect in all the enzymes tested, seeing that the maximum residual activity observed for this solvent was 58.7\% for FAE125. On the other hand, all enzymes seem to tolerate the non-polar solvents tested, such as hexane and octane, better; in this case, the residual activities obtained from most enzymes exceeded $70 \%$. Alkanes were even found to enhance enzyme activity, with residual activities exceeding $100 \%$ of the initial, for FAEB2 and FAE125. This could be partly explained by the fact that these solvents are not miscible with water, and as a result, when the enzymes are introduced in such a solvent, they tend to form hydrophilic balls, where the enzyme is protected by the enclosed space. Most enzymes seemed to perform well in the presence of acetone, with residual activities ranging from 103\% for FAE125 to $44 \%$ for FAEB2, with FAEA2 and $M t$ Faela having the lowest residual activities in this case, $20.4 \%$ and $29.2 \%$, respectively.

\subsection{Operational Stability}

Reusability is a very important factor for the selection of industrial biocatalysts for commercial applications, and CLEA use is offering this advantage in comparison to soluble enzymes. In the present work, the operational stability of the obtained FAE CLEAs was tested on eight consecutive cycles of methyl ferulate hydrolysis reactions. The results are shown in Figure 4.

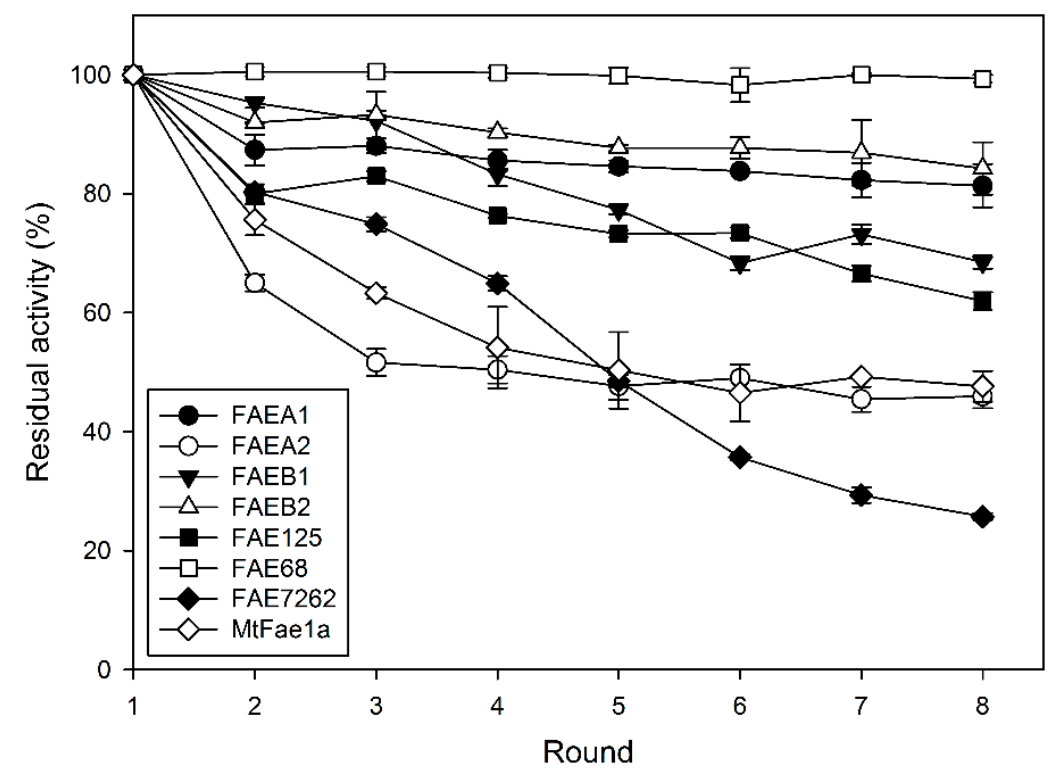

Figure 4. Operational stability of the obtained CLEAs. The residual activity is expressed as a percentage with respect to the activity determined at the first round of reactions. Reactions were performed as described in Section 4.2. Initial activity values were as follows: FAEA1 $0.75 \mathrm{U} \mathrm{mL}^{-1}$, FAEA2 $0.32 \mathrm{U} \mathrm{mL}^{-1}$, FAEB1 $0.92 \mathrm{U} \mathrm{mL}^{-1}$, FAEB2 $0.54 \mathrm{U} \mathrm{mL}^{-1}$, FAE125 $0.2 \mathrm{U} \mathrm{mL}^{-1}$, FAE68 $0.99 \mathrm{U} \mathrm{mL}^{-1}$, FAE7262 $0.77 \mathrm{U} \mathrm{mL}^{-1}, \mathrm{MtFae1a} 0.88 \mathrm{U} \mathrm{mL}^{-1}$.

The most stable CLEA was found to be FAE68, retaining almost complete activity after eight cycles of hydrolysis reactions, followed by FAEA1 and FAEB2 with $81.4 \%$ and $84.2 \%$ residual activity, respectively. FAE7262 was found to be the least stable CLEA, with only $25.7 \%$ residual activity remaining after eight cycles. However, most enzymes seem to retain at least $50 \%$ of their initial activity after three cycles of methyl ferulate (MFA) hydrolysis. 


\subsection{Structure of the Obtained CLEAs}

The SEM photographs from all CLEAs obtained at the optimum conditions are shown in Figure 5.
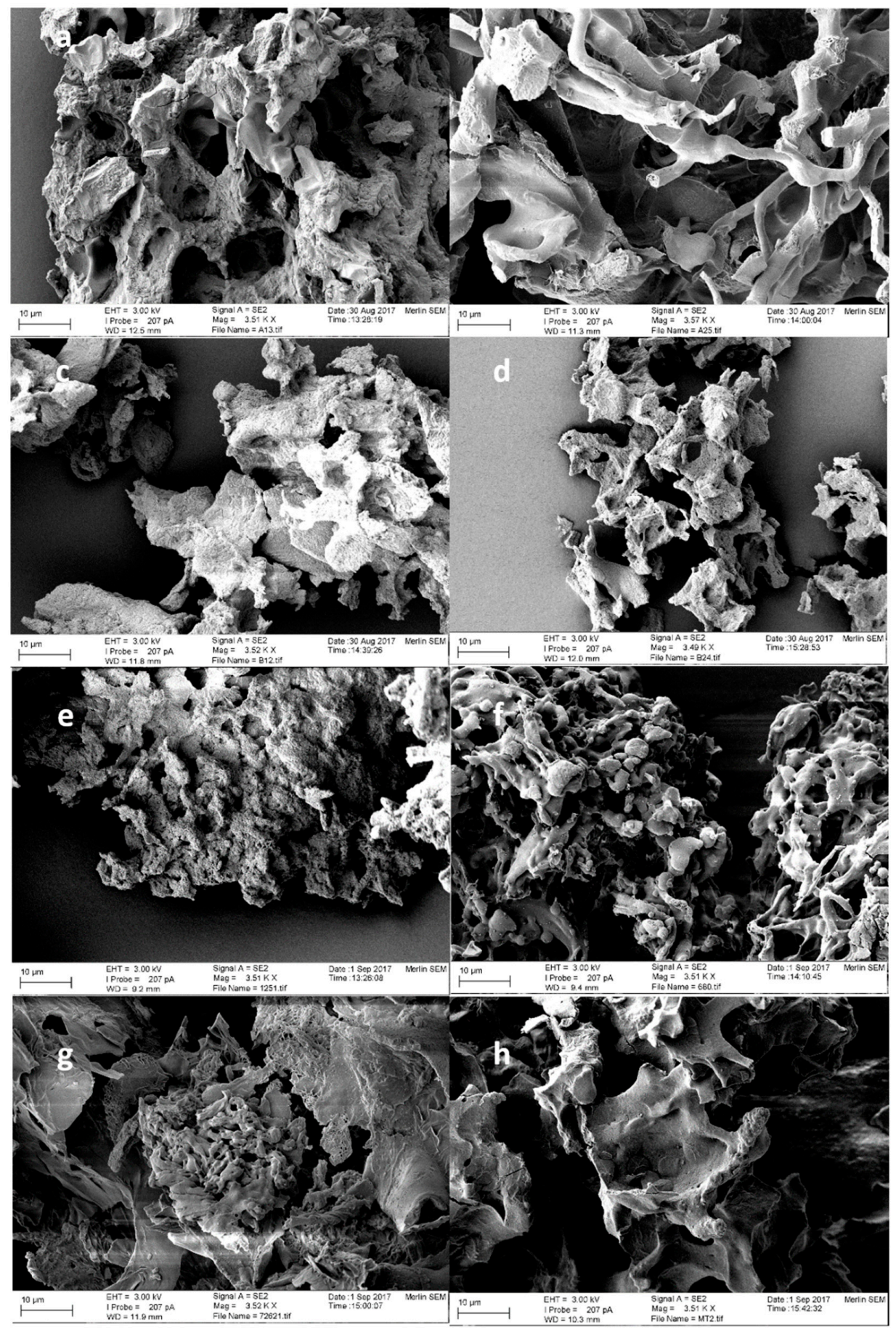

Figure 5. SEM photographs of the CLEAs obtained from all tested FAEs, at a magnification of $\sim 3500 \times$. (a) FAEA1, (b) FAEA2, (c) FAEB1, (d) FAEB2, (e) FAE125, (f) FAE68, (g) FAE7262 and (h) MtFae1a. The depicted CLEAs were prepared in optimum conditions for each FAE, namely: ammonium sulfate, $100 \mathrm{mM}$ glutaraldehyde for FAEA1 and FAE125, t-butyl alcohol, $100 \mathrm{mM}$ glutaraldehyde for FAEA2, ammonium sulfate, $200 \mathrm{mM}$ glutaraldehyde for FAEB1, ammonium sulfate, $300 \mathrm{mM}$ glutaraldehyde for FAEB2, PEG4000, 200 mM glutaraldehyde for FAE68, and PEG4000, 10 mM glutaraldehyde for FAE7262 and MtFae1a. 
Most enzyme preparations seem to form small aggregates of irregular shape, such as FAEA1, FAEA2, FAEB1, FAEB2 and FAE125. These aggregates, according to Schoevaart et al. [18], belong to the Type 2 aggregates, formed by glycosylated, hydrophilic protein molecules. However, some of the enzymes seem to form slightly more round-shaped, bigger aggregates, such as FAE68 and FAE7262. At a larger magnification (Figure 6), the Type 2 small aggregates, less than $0.1 \mu \mathrm{m}$ in diameter, are shown for FAEs B1, B2, 125 and MtFae1a, whereas FAEs 68 and 7262 seem to form round, bigger aggregates, larger than $1 \mu \mathrm{m}$ in diameter, clustered together and forming bigger surfaces.
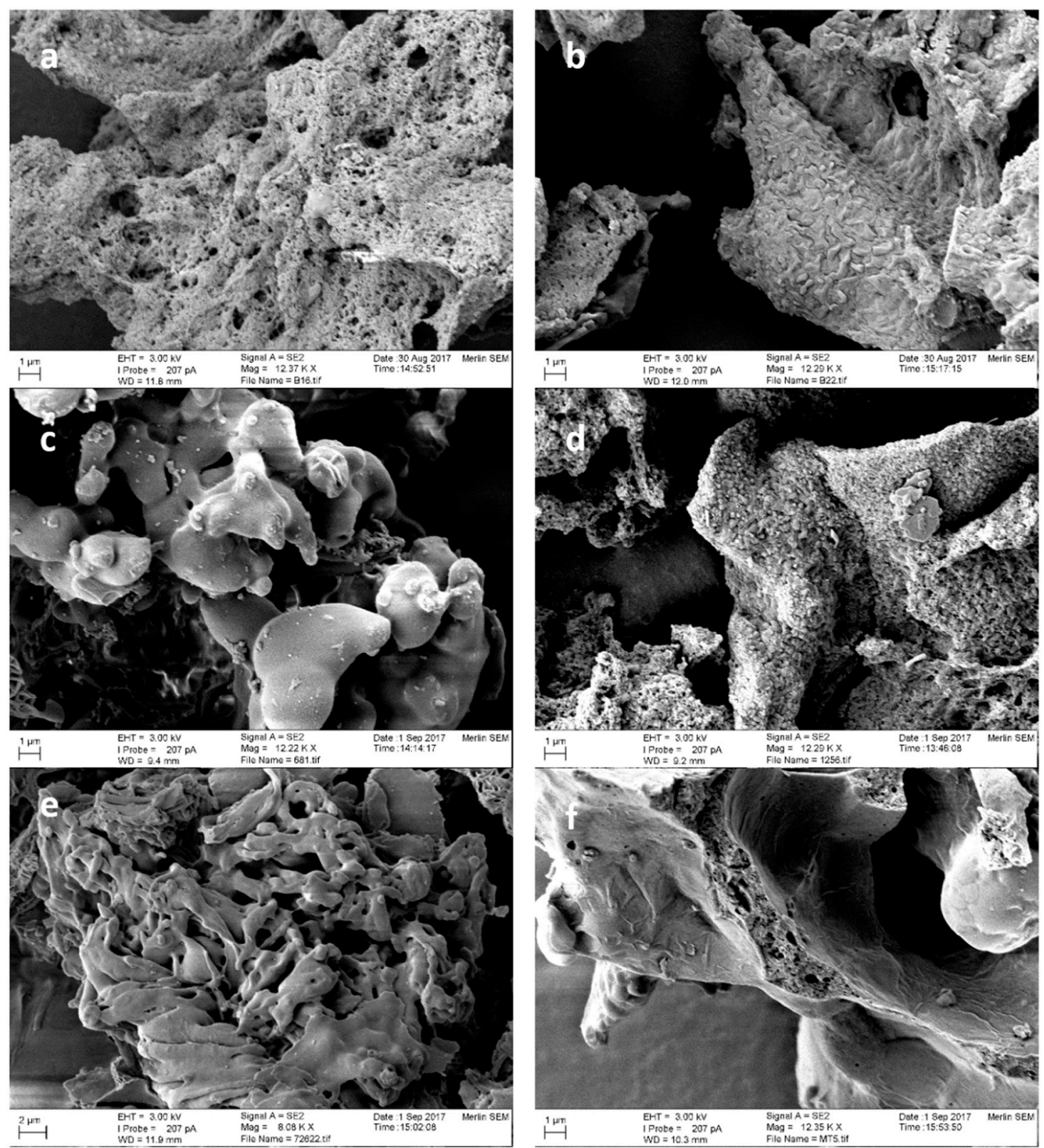

Figure 6. SEM photographs of the CLEAs obtained from FAEB1 (a), FAEB2 (b), FAE68 (c), FAE125 (d), FAE7262 (e) and MtFae1a (f), at a magnification of $\sim 12,200 \times$. The depicted CLEAs were prepared in optimum conditions for each FAE, namely: ammonium sulfate, $200 \mathrm{mM}$ glutaraldehyde for FAEB1, ammonium sulfate, 300 mM glutaraldehyde for FAEB2, PEG4000, 200 mM glutaraldehyde for FAE68, and PEG4000, $10 \mathrm{mM}$ glutaraldehyde for FAE7262 and MtFae1a. 
In an attempt to investigate the role of the precipitant in the structure formation of CLEAs, we also studied the structure of the obtained CLEAs with all tested precipitants for FAEs B2 and 7262. The results are shown in Figure 7.
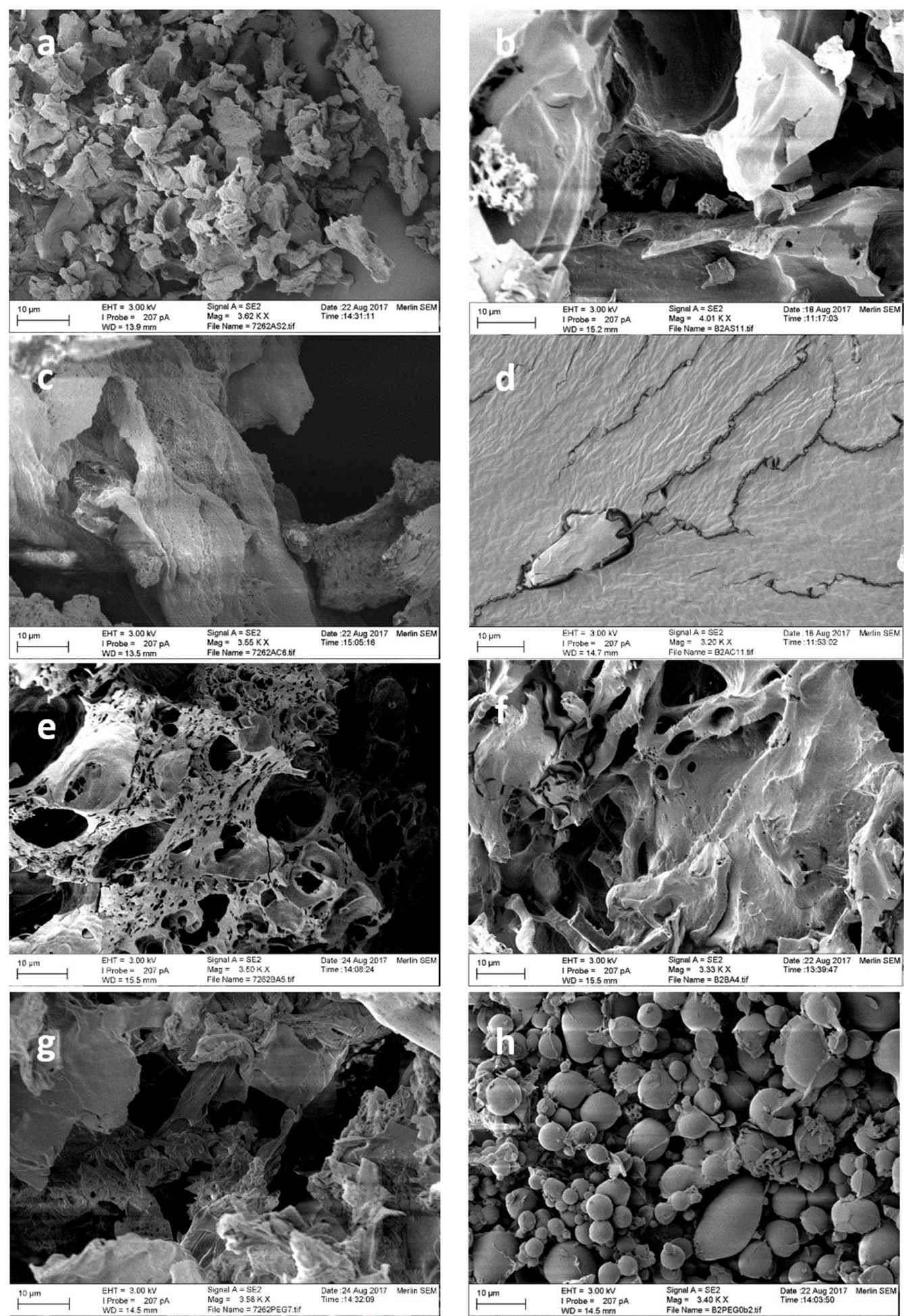

Figure 7. SEM photographs of the CLEAs obtained from FAE7262 (a,c,e,g) and FAEB2 (b,d,f,h) with different precipitants (ammonium sulfate $(\mathbf{a}, \mathbf{b})$; acetone (c,d); tert-butyl alcohol (e,f); PEG-4000 (g,h)) at magnifications of $\sim 3700 \times$. The cross-linking was achieved with $10 \mathrm{mM}$ glutaraldehyde for FAE7262 CLEAs and with $300 \mathrm{mM}$ for FAEB2 CLEAs. 
Acetone and tert-butyl alcohol seem to enhance the production of large clusters of small and irregular aggregates, in both enzyme preparations (Figure $6 \mathrm{c}-\mathrm{f}$ ). Ammonium sulfate leads to the formation of smaller size aggregates, also with irregular shape, for FAE7262, but not for FAEB2, where big clusters can be seen (Figure 6a,b). On the other hand, PEG-4000, a large hydrophilic molecule, seems to lead to the formation of slightly different aggregates: in the case of FAEB2, for example, the aggregates clearly belong to Type I, typical balls, 1-10 $\mu \mathrm{m}$ in diameter (Figure 5h). From these results, it is apparent that the type of aggregate does not always depend on the hydrophilicity of the protein sample, but also on the conditions of the immobilization, i.e., the environment of the protein sample at the time of the cross-linking.

\section{Discussion}

As mentioned earlier, CLEA immobilization is a method with significant advantages, such as low cost and simplicity, but it has to be carefully optimized for each enzyme, since the activity yield can vary greatly with the immobilization conditions [19]. In the present work, the effect of the precipitant used, together with the concentration of glutaraldehyde as a cross-linker, were tested on the residual activity of eight FAE preparations. As regards the type of the precipitant, the selected precipitants were ammonium sulfate, a very common precipitant for CLEA preparations, due to its low cost and mild effect on the protein structure; acetone, which has been used extensively in the past for the precipitation and subsequent purification of esterases [20,21]; tert-butyl alcohol, previously shown to be a suitable precipitant for FAE CLEAs [4]; and PEG-4000, a hydrophilic polymer with a stabilizing effect on the protein structure [22] that has been used before for CLEA preparation [23]. The selection of a proper precipitant might even enhance the residual activity of the obtained CLEAs, by stabilizing their structure, or by inducing a more favorable conformation of the active site towards the substrate, as shown in previous studies $[4,24,25]$. Especially acetone is reported to enhance the activity of FAEs, even in soluble form [26], while the stabilizing effects of acetone on enzyme activity have been known since 1967 [27]. For this purpose, the selection of the optimum precipitant was based on the residual activity of CLEAs after cross-linking of the precipitated FAEs. The residual activity of the obtained CLEAs was in agreement with the available data from the literature: for example, in the work of Cruz-Izquierdo et al. [28], the maximum retention of activity from Candida antarctica lipase $(48 \%)$ was observed in the case where ammonium sulfate was used as the precipitant, while the maximum residual activity of halohydrin dehalogenase from Agrobacterium radiobacter in the same conditions was 70.5\% [29]. On the other hand, in most samples precipitated with acetone and tert-butyl alcohol, a single aggregate could be observed, which could not be broken into smaller aggregates with prolonged agitation, or ultrasound treatment, in accordance with the findings of Perzon et al. [24]. These CLEAs exhibited lower residual activities, probably due to severe mass transfer limitations. These limitations might be partly due to the precipitant concentration used in this study $(90 \%)$.

Glutaraldehyde concentration seems to have a diverse impact on the residual activity of FAE CLEAs. For most FAE CLEAs, the maximum residual activity was observed in moderately high concentrations of glutaraldehyde, in agreement with the literature data $[4,29,30]$. As reported previously, glutaraldehyde concentration must be selected carefully, because too low concentrations can lead to enzyme leakage, but too high concentrations can lead to extensive clustering and therefore to a significant activity loss [31]. However, in some cases, the effect was quite different, as was the case for FAE7262 and MtFae1a, where glutaraldehyde severely hinders the enzyme activity.

The increased stability in organic solvents is one of the most important advantages of CLEAs in various synthetic applications. Feruloyl esterases have been used extensively in the literature for various (trans)esterifications [4,32] and in non-conventional systems, and thus, a certain degree of stability in non-aqueous media is necessary. In the present study, the stability in organic solvents was found to be comparable to the respective soluble FAEs. Free FAEs from Talaromyces wortmannii FAE68, FAE7262 and FAE125 showed increased stability towards apolar solvents (hexane, octane), maintaining $100 \%$ of their initial activity. However, they were less stable towards polar solvents 
(2-butanone, acetone), maintaining only $30 \%$ of their initial activity (unpublished data, [33]). In CLEA form, the destabilizing effect of 2-butanone is apparently present, but this is not the case for acetone, where their stability seems significantly improved after immobilization (Figure 3). Soluble FAEs FAE68 and FAE7262 maintained $100 \%$ of their initial activity after incubation in t-butanol, while FAE125 maintained only $52 \%$ (unpublished data, [33]). Again, the stability of FAE125 in t-butanol is enhanced after immobilization. Acetone, tert-butanol, hexane and octane were even found to enhance the activity of some CLEAs, in accordance with previous reports for soluble FAEs [26], as well as subtilisin CLEAs [34] and tyrosinase CLEAs [35]. Overall, the results regarding the enzyme stability in organic solvents can guide the selection of the most suitable solvent for a specific application, involving either a hydrolytic or a synthetic reaction.

The operational stability of most FAEs CLEA was very satisfactory, seeing that CLEAs of FAEs A1, B1, B2, 68 and 125 were found to maintain at least $60 \%$ of their initial activity after eight cycles of hydrolysis reactions, in accordance with relevant studies. For example, Penicillium notatum lipase CLEAs were found to maintain over $60 \%$ of their initial activity after 10 cycles of hydrolytic reactions [36], while $68 \%$ of initial activity was maintained by subtilisin CLEAs after 11 cycles of use [34], and combined glucose oxidase and peroxidase magnetic CLEAs were shown to maintain around $55 \%$ of their original activity after eight cycles of use [37]. These data indicate the potential of such biocatalyst preparations for use in continuous or batch commercial processes.

From all the FAE preparations tested, FAE68 was found to be the best performing enzyme in terms of immobilization yield, as well as solvent stability and reusability. The properties of FAE68 CLEAs reveal a significant potential of this biocatalyst in industrial applications regarding the isolation of ferulic acid from lignocellulosic feedstocks. This result might be partly explained by the physicochemical characteristics of FAE68 (Figure S1): this was the enzyme with a higher MW in this study, containing more lysine residues and more predicted glycosylation sites than the other FAEs. Higher lysine content might lead to better immobilization yields for obvious reasons, but also the formation of CLEA particles could have a stabilizing effect on the enzyme structure, due to the large size of the enzyme molecule.

As regards the structure of the FAE CLEAs, significant differences were observed between the CLEAs of the various FAE preparations, as well as the CLEAs of the same FAEs, but with different precipitants. The prevailing classification in the literature is the one of Schoevaart et al. [18], where typical CLEAs are classified in two types: Type I, around $1 \mu \mathrm{m}$ in diameter, with a spherical shape, and Type II, with a less structured texture and smaller size $(0.1 \mu \mathrm{m})$. In the present study, most of the FAEs seem to form Type II CLEAs, with the exceptions of MtFae1a and FAEA2, where larger clusters could be observed, similar to chemical aggregates reported previously [38]. These results are consistent with the relevant literature, since Type II aggregates are usually formed by hydrophilic, glucosylated enzymes [39] and most FAEs share these properties (Table S1). However, some variations could be observed among the FAEs studied: for example, the structures observed for FAE CLEAs 68 and 7262 appear to be more similar to the spherical shapes of Type I CLEAs. Previous studies do not indicate a correlation between the type of precipitant used and the structure of the resulting CLEAs [34], although there are a few reports correlating the structure with the precipitation conditions [40]. Our results support a certain differentiation of the final morphology depending on the precipitants used: For FAEB2, the use of ammonium sulfate, tert-butyl alcohol and acetone leads to the formation of amorphous chemical aggregates, while this kind of aggregate was formed with the use of PEG4000 in the case of FAE7262. On the other hand, Type I spherical aggregates appeared in the case where FAEB2 was precipitated with PEG4000. Type I aggregates are usually attributed to hydrophobic protein molecules with low glycosylation levels [18], but our results support the role of other parameters, such as the type of the precipitant used, for the morphology of the final product. 


\section{Materials and Methods}

\subsection{Materials and Enzymes}

Methyl ferulate (MFA) was purchased from Alfa Aesar (Karlsruhe, Germany), while FA, MOPS solution $1 \mathrm{M}$ and other materials and solvents were purchased from Sigma-Aldrich (Saint Louis, $\mathrm{MO}, \mathrm{USA})$.

The T. thermophila $\mathrm{C} 1$ genes encoding the FAEs (A1, A2, B1 and B2) were over-expressed individually in designated $\mathrm{C} 1$ strains with low-cellulase production background [41,42]. Genomic DNA sequences encoding the three putative feruloyl esterases (FAEs 68, 7262 and 125) were synthesized (GeneArt, Regensburg, Germany) and cloned in a transformation vector as previously described [42]. In each case, the resulting expression cassette containing the gene of interest under the control of a strong promoter was co-transformed with a selection marker in a $\mathrm{C} 1$ production strain. Following, the production strains were grown aerobically in a fed-batch system in minimal medium supplemented with trace elements [43]. After fermentation, the broth was centrifuged, concentrated and dialyzed to $10 \mathrm{mM}$ phosphate buffer $\mathrm{pH}$ 6.5. Samples were subsequently freeze-dried for storage. The FAE $M t$ Fae1a, sharing the same primary sequence with FAEB2, was overexpressed in Pichia pastoris as described previously [44]. The main physicochemical properties of the studied FAEs are presented in Table S1.

\subsection{Enzyme Activities}

FAEs hydrolytic activity was measured using methyl ferulate as the substrate. Duplicate enzyme samples were incubated in MOPS-NaOH buffer $\mathrm{pH}$ 6, $100 \mathrm{mM}$ with $1 \mathrm{mM}$ MFA, for $10 \mathrm{~min}$ at $45^{\circ} \mathrm{C}$ and $1300 \mathrm{rpm}$ in an Eppendorf Thermomixer Comfort (Eppendorf, Hamburg, Germany). The reaction was terminated with a 10 -min incubation in $100^{\circ} \mathrm{C}$. The amount of released ferulic acid was quantified with HPLC, as previously described [45], using the appropriate standard curves. One unit of enzyme activity corresponds to the amount of enzyme releasing $1 \mu \mathrm{mol}$ of free ferulic acid per minute in the above conditions.

\subsection{Immobilization of Enzymes}

The FAEs preparations were immobilized to CLEAs as previously described [4], following the procedure of Schoevaart et al. [18]. Briefly, $10 \mu \mathrm{L}$ of enzyme solution with $10 \%(w / v)$ protein content were added to $90 \mu \mathrm{L}$ of the selected precipitant, followed by $15 \mathrm{~min}$ incubation at room temperature and $1300 \mathrm{rpm}$. Then, $5 \mu \mathrm{L}$ of glutaraldehyde solution $(70 \mathrm{mM})$ was added to the mixture, and the crosslinking was left to proceed for $3 \mathrm{~h}$ in room temperature and $1300 \mathrm{rpm}$. The mixture was quenched in $900 \mu \mathrm{L} 100 \mathrm{mM}$ MOPS-NaOH buffer $\mathrm{pH} 6$ and centrifuged. The supernatant was assayed for FAE activity. After isolation of the precipitated CLEAs, two washing steps were performed with MOPS-NaOH buffer to remove unreacted enzyme and glutaraldehyde. Supernatants were also assayed for FAE activity, where no enzyme leakage was observed. Finally, the CLEAs were dispersed in $1 \mathrm{~mL}$ MOPS-NaOH buffer, and an aliquot was withdrawn in order to measure the activity.

\subsection{Stability of CLEAS in Organic Solvents}

The stability of the CLEA preparations towards organic solvents was tested as follows: $0.5 \mathrm{mg}$ of freeze-dried CLEAs was incubated with a mixture of 96.8:3.2 ( $v / v)$ solvent: $100 \mathrm{mM}$ MOPS-NaOH $\mathrm{pH}$ 6.0, for $24 \mathrm{~h}$ at $25^{\circ} \mathrm{C}$ in an Eppendorf thermomixer (Eppendorf, Hamburg, Germany). The tested solvents were alkanes, like hexane and octane, alcohols, like t-butanol, and ketones, like 2-butanone and acetone. After $24 \mathrm{~h}$, a 20- $\mu \mathrm{L}$ aliquot was withdrawn and assayed for FAE activity. For the sampling of hexane- and octane-CLEAs mixtures, where the enzyme and the buffer formed a separate water phase, the solvent was removed, and the water phase was diluted to $1 \mathrm{~mL}$ with buffer, before sampling for the activity assay. The residual activity is expressed as a percentage of remaining activity compared with the incubation of the appropriate amount of CLEAs in $\mathrm{dH}_{2} \mathrm{O}$ for $24 \mathrm{~h}$ at $25^{\circ} \mathrm{C}$. 


\subsection{Operational Stability}

In order to estimate the operational stability of the obtained CLEAs on the hydrolysis of MFA, $100 \mu \mathrm{L}$ of CLEA suspensions were added to $900 \mu \mathrm{L}$ MOPS-NaOH buffer $(100 \mathrm{mM}$, pH 6), with $1 \mathrm{mM}$ MFA. The mixture was incubated for $10 \mathrm{~min}$ at $45{ }^{\circ} \mathrm{C}$ at $1300 \mathrm{rpm}$ in an Eppendorf thermomixer. The CLEA particles were recovered by centrifugation at $4{ }^{\circ} \mathrm{C}$, while the supernatant was boiled for $10 \mathrm{~min}$, in order to deactivate possible leached enzyme activity. The obtained CLEAs were then used for the next round of reactions, while the supernatant was analyzed with HPLC as previously described. Overall, the residual activity of the CLEAs was studied for eight reaction cycles, and it is expressed as a percentage with reference to the initial activity.

\subsection{Structure of CLEAs}

Prior to the structural analysis, freeze-dried CLEA samples were coated with a thin layer of gold. A high-resolution field-emission gun scanning electron microscope, Zeiss Merlin, fitted with an Oxford Instruments large-area energy dispersive spectrometer (FEG-SEM-EDS) was then used for the structure analysis of the CLEA samples. The analytical settings used were an accelerating voltage of $3.0 \mathrm{kV}$ and a 207-pA beam current.

\section{Conclusions}

In the present work, a wide selection of feruloyl esterase preparations was immobilized using the CLEA $^{\circledR}$ technology. The optimum immobilization conditions were investigated for every FAE, and the resulting CLEAs were characterized. Our results support the necessity of the optimization of the CLEA formation parameters for each enzyme, due to great variations in the optimum immobilization conditions found for the tested preparations. From the SEM analysis, we concluded that the precipitant selection is a critical parameter for the structure of the final product, but the nature of the enzyme is also affecting the resulting aggregates. Most of the obtained CLEAs showed a very satisfactory reusability and stability in organic solvents. Overall, we concluded that CLEA immobilization of industrially-relevant biocatalysts has the potential to significantly lower the cost of commercial lignocellulose biorefinery applications, with the ability to reuse the catalysts several times, or by implementing a continuous process.

Supplementary Materials: The following are available online at http:/ /www.mdpi.com/2073-4344/8/5/208/s1. Table S1: Physicochemical properties of the studied FAEs. Figure S1: Residual FAE activity (\%) of the soluble enzyme in the supernatant after CLEA removal, for all tested glutaraldehyde concentrations. Residual activity is presented as a percentage of the initial activity of the corresponding free enzymes. Reactions were performed as described in Section 4.2. Initial activity values for each FAE were as follows: FAEA1 $1.85 \mathrm{U} \mathrm{mL}^{-1}$, FAEA2 3.36 U mL $\mathrm{UL}^{-1}$, FAEB1 $3.57 \mathrm{U} \mathrm{mL}^{-1}$, FAEB2 $2.62 \mathrm{U} \mathrm{mL}^{-1}$, FAE125 $1.25 \mathrm{U} \mathrm{mL}^{-1}$, FAE68 $4.98 \mathrm{U} \mathrm{mL}^{-1}$, FAE7262 3.38 $\mathrm{U} \mathrm{mL}^{-1}, M t$ Fae1a $2.71 \mathrm{U} \mathrm{mL}^{-1}$.

Author Contributions: A.Z. designed, performed the experiments, analyzed the data and wrote the manuscript. I.A. analyzed the activity data and wrote the manuscript. J.E. performed the SEM analysis and wrote the manuscript. U.R. and P.C. conceived of the concept of the work, designed and analyzed experimental data. L.I. produced FaeA1, FaeA2, FaeB1 and FaeB2 from T. thermophila C1 and FAE68, FAE7262 and FAE125 from Talaromyces wortmannii. All authors revised the manuscript.

Acknowledgments: This work was supported by a grant from European Union large-scale integrating project targeted at SMEs "Optimized esterase biocatalysts for cost-effective industrial production (OPTIBIOCAT)", Grant Agreement No. 613868, co-funded within the FP7 Knowledge Based Bio-Economy (KBBE).

Conflicts of Interest: The authors declare no conflict of interest. The funding sponsors had no role in the design of the study; in the collection, analyses or interpretation of data; in the writing of the manuscript; nor in the decision to publish the results. 


\section{References}

1. Sheldon, R.A. Cross-linked enzyme aggregates $\left(\mathrm{CLEA}^{\circledR} \mathrm{s}\right)$ : Stable and recyclable biocatalysts. Biochem. Soc. Trans. 2007, 35, 1583-1587. [CrossRef] [PubMed]

2. Thörn, C.; Gustafsson, H.; Olsson, L. Immobilization of feruloyl esterases in mesoporous materials leads to improved transesterification yield. J. Mol. Catal. B Enzym. 2011, 72, 57-64. [CrossRef]

3. Mateo, C.; Palomo, J.M.; van Langen, L.M.; van Rantwijk, F.; Sheldon, R.A. A new, mild cross-linking methodology to prepare cross-linked enzyme aggregates. Biotechnol. Bioeng. 2004, 86, 273-276. [CrossRef] [PubMed]

4. Vafiadi, C.; Topakas, E.; Christakopoulos, P. Preparation of multipurpose cross-linked enzyme aggregates and their application to production of alkyl ferulates. J. Mol. Catal. B Enzym. 2008, 54, 35-41. [CrossRef]

5. De Winter, K.; Soetaert, W.; Desmet, T. An imprinted cross-linked enzyme aggregate (iCLEA) of sucrose phosphorylase: Combining improved stability with altered specificity. Int. J. Mol. Sci. 2012, 13, 11333-11342. [CrossRef] [PubMed]

6. Yan, J.; Gui, X.; Wang, G.; Yan, Y. Improving stability and activity of cross-linked enzyme aggregates based on polyethylenimine in hydrolysis of fish oil for enrichment of polyunsaturated fatty acids. Appl. Biochem. Biotechnol. 2012, 166, 925-932. [CrossRef] [PubMed]

7. Ba, S.; Jones, J.P.; Cabana, H. Hybrid bioreactor (HBR) of hollow fiber microfilter membrane and cross-linked laccase aggregates eliminate aromatic pharmaceuticals in wastewaters. J. Hazard. Mater. 2014, 280 (Suppl. C), 662-670. [CrossRef] [PubMed]

8. Cabana, H.; Jones, J.P.; Agathos, S.N. Utilization of cross-linked laccase aggregates in a perfusion basket reactor for the continuous elimination of endocrine-disrupting chemicals. Biotechnol. Bioeng. 2009, 102, 1582-1592. [CrossRef] [PubMed]

9. Wong, D.W. Feruloyl esterase: A key enzyme in biomass degradation. Appl. Biochem. Biotechnol. 2006, 133, 87-112. [CrossRef]

10. Faulds, C.B.; Williamson, G. Release of ferulic acid from wheat bran by a ferulic acid esterase (FAE III) from Aspergillus niger. Appl. Microbiol. Biotechnol. 1995, 43, 1082-1807. [CrossRef] [PubMed]

11. Benoit, I.; Navarro, D.; Marnet, N.; Rakotomanomana, N.; Lesage-Meessen, L.; Sigoillot, J.C.; Asther, M.; Asther, M. Feruloyl esterases as a tool for the release of phenolic compounds from agro-industrial by-products. Carbohydr. Res. 2006, 341, 1820-1827. [CrossRef] [PubMed]

12. Bartolome, B.; Faulds, C.B.; Williamson, G. Enzymic release of ferulic acid from barley spent grain. J. Cereal Sci. 1997, 25, 285-288. [CrossRef]

13. Okada, T.; Nakagawa, K.; Yamaguchi, N. Antioxidative activities of amino compounds on fats and oils: VIII. Antioxidative activity of ferulate and the synergistic effect of amino compounds. Nippon Shokuhin Kogyo Gakkaishi 1982, 29, 305-309. [CrossRef]

14. Topakas, E.; Vafiadi, C.; Christakopoulos, P. Microbial production, characterization and applications of feruloyl esterases. Process Biochem. 2007, 42, 497-509. [CrossRef]

15. Xu, Z.; He, H.; Zhang, S.; Guo, T.; Kong, J. Characterization of Feruloyl Esterases Produced by the Four Lactobacillus Species: L. amylovorus, L. acidophilus, L. farciminis and L. fermentum, Isolated from Ensiled Corn Stover. Front. Microbiol. 2017, 8, 941. [CrossRef] [PubMed]

16. Kelle, S.; Nieter, A.; Krings, U.; Zelena, K.; Linke, D.; Berger, R.G. Heterologous production of a feruloyl esterase from Pleurotus sapidus synthesizing feruloyl-saccharide esters. Biotechnol. Appl. Biochem. 2016, 63, 852-862. [CrossRef] [PubMed]

17. Watanabe, M.; Yoshida, E.; Fukada, H.; Inoue, H.; Tokura, M.; Ishikawa, K. Characterization of a feruloyl esterase B from Talaromyces cellulolyticus. Biosci. Biotechnol. Biochem. 2015, 79, 1845-1851. [CrossRef] [PubMed]

18. Schoevaart, R.; Wolbers, M.W.; Golubovic, M.; Ottens, M.; Kieboom, A.P.; van Rantwijk, F.; van der Wielen, L.A.; Sheldon, R.A. Preparation, optimization, and structures of cross-linked enzyme aggregates (CLEAs). Biotechnol. Bioeng. 2004, 87, 754-762. [CrossRef] [PubMed]

19. De Rose, S.A.; Novak, H.; Dowd, A.; Singh, S.; Lang, D.A.; Littlechild, J. Stabilization of a Lipolytic Enzyme for Commercial Application. Catalysts 2017, 7, 91. [CrossRef]

20. White, B.T. A Method for the Isolation of Bovine Liver Esterase. J. Dairy Sci. 1956, 39, 547-551. [CrossRef]

21. Basaran, P.; Hang, Y.D. Purification and characterization of acetyl esterase from Candida guilliermondii. Lett. Appl. Microbiol. 2000, 30, 167-171. [CrossRef] [PubMed] 
22. Rawat, S.; Raman Suri, C.; Sahoo, D.K. Molecular mechanism of polyethylene glycol mediated stabilization of protein. Biochem. Biophys. Res. Commun. 2010, 392, 561-566. [CrossRef] [PubMed]

23. Zheng, J.; Chen, Y.; Yang, L.; Li, M.; Zhang, J. Preparation of Cross-Linked Enzyme Aggregates of Trehalose Synthase via Co-aggregation with Polyethyleneimine. Appl. Biochem. Biotechnol. 2014, 174, 2067-2078. [CrossRef] [PubMed]

24. Perzon, A.; Dicko, C.; Çobanoğlu, Ö.; Yükselen, O.; Eryilmaz, J.; Dey, E.S. Cellulase cross-linked enzyme aggregates (CLEA) activities can be modulated and enhanced by precipitant selection. J. Chem. Technol. Biotechnol. 2017, 92, 1645-1649. [CrossRef]

25. López-Serrano, P.; Cao, L.; van Rantwijk, F.; Sheldon, R.A. Cross-linked enzyme aggregates with enhanced activity: Application to lipases. Biotechnol. Lett. 2002, 24, 1379-1383. [CrossRef]

26. Faulds, C.B.; Perez-Boada, M.; Martinez, A.T. Influence of organic co-solvents on the activity and substrate specificity of feruloyl esterases. Bioresour. Technol. 2011, 102, 4962-4967. [CrossRef] [PubMed]

27. Takemori, S.; Furuya, E.; Suzuki, H.; Katagiri, M. Stabilization of Enzyme Activity by an Organic Solvent. Nature 1967, 215, 417. [CrossRef] [PubMed]

28. Cruz-Izquierdo, Á.; Picó, E.A.; López, C.; Serra, J.L.; Llama, M.J. Magnetic Cross-Linked Enzyme Aggregates (mCLEAs) of Candida antarctica Lipase: An Efficient and Stable Biocatalyst for Biodiesel Synthesis. PLoS ONE 2015, 9, e115202. [CrossRef] [PubMed]

29. Liao, Q.; Du, X.; Jiang, W.; Tong, Y.; Zhao, Z.; Fang, R.; Feng, J.; Tang, L. Cross-linked enzyme aggregates (CLEAs) of halohydrin dehalogenase from Agrobacterium radiobacter AD1: Preparation, characterization and application as a biocatalyst. J. Biotechnol. 2018, 272-273, 48-55. [CrossRef] [PubMed]

30. Taboada-Puig, R.; Junghanns, C.; Demarche, P.; Moreira, M.T.; Feijoo, G.; Lema, J.M.; Agathos, S.N. Combined cross-linked enzyme aggregates from versatile peroxidase and glucose oxidase: Production, partial characterization and application for the elimination of endocrine disruptors. Bioresour. Technol. 2011, 102, 6593-6599. [CrossRef] [PubMed]

31. Cui, J.D.; Jia, S.R. Optimization protocols and improved strategies of cross-linked enzyme aggregates technology: Current development and future challenges. Crit. Rev. Biotechnol. 2015, 35, 15-28. [CrossRef] [PubMed]

32. Antonopoulou, I.; Leonov, L.; Jütten, P.; Cerullo, G.; Faraco, V.; Papadopoulou, A.; Kletsas, D.; Ralli, M.; Rova, U.; Christakopoulos, P. Optimized synthesis of novel prenyl ferulate performed by feruloyl esterases from Myceliophthora thermophila in microemulsions. Appl. Microbiol. Biotechnol. 2017, 101, 3213-3226. [CrossRef] [PubMed]

33. Antonopoulou, I.; Iancu, L.; Jutten, P.; Piechot, A.; Rova, U.; Christakopoulos, P. Optimization of enzymatic synthesis of antioxidants catalyzed by a novel feruloyl esterase from Talaromyces wortmanii (Fae125) in hexane via response surface methodology. 2018, submitted.

34. Sangeetha, K.; Abraham, E.T. Preparation and characterization of cross-linked enzyme aggregates (CLEA) of Subtilisin for controlled release applications. Int. J. Biol. Macromol. 2008, 43, 314-319. [CrossRef] [PubMed]

35. Xu, D.Y.; Yang, Y.; Yang, Z. Activity and stability of cross-linked tyrosinase aggregates in aqueous and nonaqueous media. J. Biotechnol. 2011, 152, 30-36. [CrossRef] [PubMed]

36. Rehman, S.; Bhatti, H.N.; Bilal, M.; Asgher, M. Cross-linked enzyme aggregates (CLEAs) of Pencilluim notatum lipase enzyme with improved activity, stability and reusability characteristics. Int. J. Biol. Macromol. 2016, 91, 1161-1169. [CrossRef] [PubMed]

37. Zhou, L.; Tang, W.; Jiang, Y.; Ma, L.; He, Y.; Gao, J. Magnetic combined cross-linked enzyme aggregates of horseradish peroxidase and glucose oxidase: An efficient biocatalyst for dye decolourization. RSC Adv. 2016, 6, 90061-90068. [CrossRef]

38. Tyagi, R.; Batra, R.; Gupta, M.N. Amorphous enzyme aggregates: Stability toward heat and aqueous-organic cosolvent mixtures. Enzyme Microb. Technol. 1999, 24, 348-354. [CrossRef]

39. Velasco-Lozano, S.; López-Gallego, F.; Mateos-Díaz, J.C.; Favela-Torres, E. Cross-linked enzyme aggregates (CLEA) in enzyme improvement-A review. Biocatalysis 2016, 1, 166. [CrossRef]

40. Aytar, B.S.; Bakir, U. Preparation of cross-linked tyrosinase aggregates. Process Biochem. 2008, 43, $125-131$. [CrossRef]

41. Kühnel, S.; Pouvreau, L.; Appeldoorn, M.M.; Hinz, S.W.; Schols, H.A.; Gruppen, H. The ferulic acid esterases of Chrysosporium lucknowense C1: Purification, characterization and their potential application in biorefinery. Enzyme Microb. Technol. 2012, 50, 77-85. [CrossRef] [PubMed] 
42. Visser, H.; Joosten, V.; Punt, P.J.; Gusakov, A.V.; Olson, P.T.; Joosten, R.; Bartels, J.; Visser, J.; Sinitsyn, A.P.; Emalfarb, M.A.; et al. Development of a mature fungal technology and production platform for industrial enzymes based on a Myceliophthora thermophila isolate, previously known as Chrysosporium lucknowense C1. Ind. Biotechnol. 2011, 7, 214-223. [CrossRef]

43. Verdoes, J.C.; Punt, P.J.; Burlingame, R.; Bartels, J.; van Dijk, R.; Slump, E.; Meens, M.; Joosten, R.; Emalfarb, M. A dedicated vector for efficient library construction and high throughput screening in the hyphal fungus Chrysosporium lucknowense. Ind. Biotechnol. 2007, 3, 48-57. [CrossRef]

44. Topakas, E.; Moukouli, M.; Dimarogona, M.; Christakopoulos, P. Expression, characterization and structural modelling of a feruloyl esterase from the thermophilic fungus Myceliophthora thermophila. Appl. Microbiol. Biotechnol. 2012, 94, 399-411. [CrossRef] [PubMed]

45. Topakas, E.; Stamatis, H.; Biely, P.; Kekos, D.; Macris, B.J.; Christakopoulos, P. Purification and characterization of a feruloyl esterase from Fusarium oxysporum catalyzing esterification of phenolic acids in ternary water-organic solvent mixtures. J. Biotechnol. 2003, 102, 33-44. [CrossRef]

(C) 2018 by the authors. Licensee MDPI, Basel, Switzerland. This article is an open access article distributed under the terms and conditions of the Creative Commons Attribution (CC BY) license (http:// creativecommons.org/licenses/by/4.0/). 